\title{
TITLE:
}

\section{Influence of neutral inorganic chlorides on primary and secondary char formation from cellulose}

\section{$\operatorname{AUTHOR}(S)$ :}

Kawamoto, Haruo; Yamamoto, Daisuke; Saka, Shiro

\section{CITATION:}

Kawamoto, Haruo ... [et al]. Influence of neutral inorganic chlorides on primary and secondary char formation from cellulose. Journal of Wood Science 2008, 54(3): 242-246

\section{ISSUE DATE:}

2008-06

URL:

http://hdl.handle.net/2433/240658

\section{RIGHT:}

This is a post-peer-review, pre-copyedit version of an article published in 'Journal of Wood Science'. The final authenticated version is available online at: https://doi.org/10.1007/s10086-007-0930-8.; The full-text file will be made open to the public on 1 June 2009 in accordance with publisher's 'Terms and Conditions for Self-Archiving',; この論文は 出版社版でありません。引用の際には出版社版をご確認で利用ください。; This is not the published version. Please cite only the published version. 


\section{Title Page}

Original Article

\section{Title: Influence of neutral inorganic chlorides on primary and secondary char formation from cellulose}

Authors: Haruo Kawamoto • Daisuke Yamamoto • Shiro Saka

Haruo Kawamoto $(\bowtie) \cdot$ Daisuke Yamamoto $\cdot$ Shiro Saka

Department of Socio-Environmental Energy Science, Graduate School of Energy

Science, Kyoto University, Yoshida Hon-machi, Sakyo-ku, Kyoto 606-8501, Japan

Tel/Fax: +81-(0) 75-753-4737

E-mail:kawamoto@energy.kyoto-u.ac.jp

Keywords: cellulose, carbonization, primary char, secondary char, alkali metal chloride, alkaline earth metal chloride 
Abstract: Influence of various alkali and alkaline earth metal chlorides ( $\mathrm{LiCl}, \mathrm{NaCl}$, $\mathrm{KCl}, \mathrm{MgCl}_{2}$ and $\mathrm{CaCl}_{2}$ ) on primary and secondary char formation from cellulose was studied at $400^{\circ} \mathrm{C}$. Secondary char was formed through secondary carbonization of the volatile products. All chlorides increased the primary char yield with decreasing the secondary char formation, and this situation was promoted in the order of alkaline earth Mg, Ca, alkali Li > alkali Na, K. Levoglucosan yield also decreased along with the secondary char yield. These results indicate that the reduced formation of volatile levoglucosan had relation to the decreasing yield of secondary char. Model experiment at $250{ }^{\circ} \mathrm{C}$ revealed that these chlorides, especially the two alkaline earth metals, had the catalytic action on the polymerization of levoglucosan. This catalytic polymerization would reduce the formation of volatile levoglucosan. 


\section{Introduction}

Wood pyrolysis is the fundamental principle of various thermochemical processes of woody biomass such as carbonization, gasification and fast pyrolysis. The knowledge of the pyrolysis mechanism on a molecular basis is thus helpful to improve these conversion processes, i.e., increasing the product selectivity, allevating the tar trouble in gasification and so on. This article focuses on the inorganic matter, that affects the pyrolysis reactions of cellulose greatly.

Influence of the inorganic matter on cellulose pyrolysis has been studied extensively, for understanding the behavior of woody biomass in thermochemical conversion processes. $^{1-18}$ Demineralization by acid washing the samples prior to pyrolysis usually increases the levoglucosan (1,6-anhydro- $\beta$-D-glucopyranoside) yield and reduces the char formation. ${ }^{1-3,5}$ Influence of individual inorganic substance on cellulose pyrolysis has also been studied with ion-exchanged 6-8 and impregnated 2, 9-13 samples. According to the findings, the acidic substances enhance the formation of the dehydration products such as levoglucosenone and furfural, while some fragmented products including glycolaldehyde and hydroxyacetone are formed more preferentially with the basic substances. ${ }^{15-18}$ Some of these aspects are explained on the basis of their acidity and basicity. However, action of the neutral salts on cellulose pyrolysis is still unknown on a molecular basis.

As for neutral salts, many studies employed alkali metal halides. ${ }^{2,9-11,14}$ These halides are found to lower the degradation temperature slightly ${ }^{2,11}$ and enhance the formation of char, $\mathrm{CO}, \mathrm{CO}_{2}$ and $\mathrm{H}_{2} \mathrm{O}^{13,14}$ with reducing the yield of levoglucosan. ${ }^{9,13}$ Shafizadeh and Sekiguchi ${ }^{12}$ reported by analyzing mellitic acid that NaCl-addition enhanced the formation of aromatic structures. There are, however, very few papers 
which describe the influence of alkaline earth metal halides. ${ }^{4,11}$

Attention should be paid to the situation that a considerable amount of carbonized products (defined as "secondary char" in this article) was formed from the secondary carbonization of the volatile products after condensing near the outlet of the reactor with relatively low temperature. Practically, this type of char formation would be related to the clogging of the pyrolysis reactor. In our previous papers, ${ }^{19,} 20$ ring-opening polymerization of levoglucosan has been proposed as a key reaction to the carbonization. This secondary carbonization is also expected to be influenced by inorganic matter through changing the product compositions. However, the influence on the secondary carbonization has not been reported yet.

In this article, the action of alkali and alkaline earth metal chlorides on primary and secondary char formation is described by focusing on levoglucosan as a key intermediate to the secondary char formation.

\section{Experimental}

Materials

Filter paper (Kiriyama Glass Co., oven dried at $105^{\circ} \mathrm{C}$ for $24 \mathrm{~h}$ ) was used as a cellulose sample. Aqueous $\mathrm{LiCl}, \mathrm{NaCl}, \mathrm{KCl}, \mathrm{MgCl}_{2}$ or $\mathrm{CaCl}_{2}$ solution $(0.10,0.050$ or $0.010 \mathrm{mmol}$ in $150 \mu \mathrm{l}$ ) was added dropwise to the filter paper (37 mg). This amount of solution was completely absorbed by the filter paper. The resulting filter paper was dried in an oven at $105^{\circ} \mathrm{C}$ for $24 \mathrm{~h}$ before pyrolysis. The amount of the impregnation was $0.44,0.22$ and $0.044 \mathrm{~mol} / \mathrm{mol}$ of the glucose-unit of cellulose. Control sample was also prepared with pure water (150 $\mu \mathrm{l})$ by the similar way. 
Pyrolysis and product characterization

Pyrolysis was conducted with the apparatus reported in the previous paper. ${ }^{19}$ Sample was placed at the bottom of a round-shaped flask (30 ml volume) and the flask was attached with a cooling tube (120 mm long and $14 \mathrm{~mm}$ in diameter) and a nitrogen bag through a three-way tap. After replacing the air in the system with nitrogen, the flask was soaked in a salt bath $\left(\mathrm{KNO}_{3} / \mathrm{NaNO}_{3}, 1: 1\right.$, w/w $)\left(400{ }^{\circ} \mathrm{C}\right)$ for $10 \mathrm{~min}$. The flask was immediately cooled with flowing air (30 s) and subsequently in cold water (3 min), and the carbonized paper (defined as "primary char" in this paper, Fig. 1) was taken out of the flask and weighed. The amount of the primary char was calculated by subtracting the weight of the chloride in the original paper from the weight of the carbonized paper, on the assumption that all the chloride could be included in the carbonized paper. The flask and the cooling tube were extracted with $\mathrm{MeOH}(5.0 \mathrm{ml})$ to give a MeOH-soluble fraction. The carbonized substance, which was observed near the top of the flask, is defined as "secondary char" in this paper (Fig. 1). The secondary char which was sticking on the wall of the flask was washed with water (5.0 ml) and dried before weighing. The amounts of the MeOH-soluble products and secondary char were calculated from the weight-difference of the glass ware before and after extraction. The MeOH-soluble fractions were analyzed by GPC with a Shimadzu LC-10A (column: Asahipak GS-220 HQ, eluent: water, flow rate: $1.0 \mathrm{ml} / \mathrm{min}$, detector: RID, temperature: $\left.40^{\circ} \mathrm{C}\right)$.

Influence on levoglucosan polymerization 
Levoglucosan (8.1 mg, $0.050 \mathrm{mmol})$ was taken into a round-shaped flask (30 ml) and dissolved in a chloride aqueous solution $(0.0050 \mathrm{mmol}$ in $0.10 \mathrm{ml})$. The resulting solution was evaporated in vacuo to form a thin film at the bottom of the flask. Heat treatment was conducted in $\mathrm{N}_{2}$ with the similar apparatus as described in the pyrolysis section. To avoid the formation of the carbonization products, which make the investigation of the polymerization reactivity difficult, $250^{\circ} \mathrm{C}$ was chosen as a heating temperature. After $1 \mathrm{~min}$ heating at $250^{\circ} \mathrm{C}$, reaction was quenched by cooling with flowing air (30 s) and in cold water (3 min). The reaction mixture was extracted with water $(0.5 \mathrm{ml})$ and analyzed with GPC under the chromatographic conditions described above.

\section{Results and discussion}

Figure 2 summarizes the primary and secondary char yields at various chloride-addition-levels. Dotted line shows the total char yield [23\%, primary $(7 \%)+$ secondary (16\%)] in pure cellulose (neat). With addition of chloride, the primary char yield increased up to 16 - 54\% (excluding the amount of chloride) with decreasing the secondary char yield $(0-16 \%)$. This situation was promoted with the increasing addition-level.

Alkaline earth metals $\left(\mathrm{MgCl}_{2}, \mathrm{CaCl}_{2}\right)$ exhibited much greater influences than alkali metals $(\mathrm{NaCl}, \mathrm{KCl})$ except for $\mathrm{LiCl}$. The influence of $\mathrm{LiCl}$ was rather similar to those of the alkaline earth metals. $\mathrm{Mg}(0.22,0.44 \mathrm{~mol})$, Ca (0.22, $0.44 \mathrm{~mol})$ and $\mathrm{Li}(0.44$ mol) reduced the secondary char yields up to undetectable levels, while the primary char yields increased about 3.6 - 7.3 times as compared with pure cellulose. Consequently, their total char yields substantially increased $(1.5-2.3$ times). Contrary to this, the 
total char yields from the $\mathrm{NaCl}$ - and $\mathrm{KCl}$-impregnated samples were not affected greatly (1.2 - 1.5 times).

Gel permeation chromatograms of the $\mathrm{MeOH}$-soluble fractions at $0.44 \mathrm{~mol} / \mathrm{mol}$ of the glucose-unit are shown in Fig. 3. The peak area in the chromatogram decreased in the order of neat $>\mathrm{Na}, \mathrm{K}>\mathrm{Li}, \mathrm{Mg}$, $\mathrm{Ca}$, and this order was quite similar to that observed in the secondary char formation. The peak areas at $10 \mathrm{~min}$, which correspond to the yield of levoglucosan, were reduced by Na-, K- and Ca-impregnation, and levoglucosan was not detected from the Li- and Mg-impregnated samples. Figure 4 summarizes the primary, secondary and total char yields as plotted against the levoglucosan yields. Some positive correlation existed between the secondary char and levoglucosan yields, while the primary char yield was negatively correlated with the levoglucosan yield. Due to these opposite relationships between primary and secondary char yields, the total char yields from the neat and Na- and K-impregnated samples were almost independent of the levoglucosan yield.

Influence of the chlorides on the polymerization of levoglucosan is discussed from the GPC chromatograms measured for the heat treated mixtures of levoglucosan and chlorides $\left(1: 0.1, \mathrm{~mol} / \mathrm{mol}, \mathrm{N}_{2} / 250^{\circ} \mathrm{C} / 1 \mathrm{~min}\right)$ in Fig. $5 . \quad$ Intensity of the peak area observed in the higher MW region than levoglucosan increased with addition of chloride. Polymerization reactivity was evaluated by introducing the "polymerization index”, which is defined as equation (1).

Peak area (higher MW region than levoglucosan) / peak area (levoglucosan)

The larger the polymerization index becomes, the greater is the catalytic activity. The obtained polymerization indexes are summarized in Fig. 6. All these chlorides had the 
catalytic action on the polymerization of levoglucosan. The alkaline earth metals, which substantially increased the primary and total char yields had especially high catalytic activities. The catalytic activity of $\mathrm{LiCl}$ was weak like other alkali metals, although the enhancing effect on the primary char formation was much greater than $\mathrm{NaCl}$ and $\mathrm{KCl}$.

Based on these lines of evidence, the influence of alkali and alkaline earth metal chlorides on primary and secondary char formation from cellulose is discussed in termed of the formation of volatile levoglucosan. In pure cellulose, substantial amount of levoglucosan vaporizes and condenses at the reactor-wall with lower temperature, where levoglucosan is subject to secondary carbonization (Fig. 7). Consequently, secondary char yield depends on the amount of volatile levoglucosan. Kawamoto et al. 19, 20 have reported that the ring-opening polymerization of levoglucosan is a key reaction for the carbonization. Reduction of the amount of volatile levoglucosan induced by alkali and alkaline earth metal chlorides would be related to the inhibition of the secondary char formation.

The catalytic action of these chlorides on the polymerization of levoglucosan would reduce the amount of volatile levoglucosan, although they would have complex action on cellulose pyrolysis. In the following paper, ${ }^{21}$ the action of $\mathrm{MgCl}_{2}$ and $\mathrm{CaCl}_{2}$ as Lewis acids to promote the solid-state hydrolysis have been found at elevated temperature. Affinity of $\mathrm{Mg}^{2+}$ or $\mathrm{Ca}^{2+}$ to the ring-oxygen of levoglucosan has been used to explain the catalytic activity. Relatively strong influence of $\mathrm{LiCl}$ on cellulose carbonization, which has low catalytic activity, suggests that other mechanisms also play important roles, although further study is necessary to clarify the mechanism.

\section{Conclusions}


Alkali and alkaline earth metal chlorides increased the primary char yield with inhibiting the secondary char formation. The yield of levoglucosan, the important intermediate in cellulose pyrolysis, also substantially reduced with these salts. Especially strong actions were observed for the alkaline earth metal chlorides, and these chlorides had the strong catalytic activities on the polymerization of levoglucosan. Based on these results, inhibition of the secondary char formation would be related to the reduced formation of volatile levoglucosan in the presence of these salts. 


\section{References}

1. Hosoya T, Kawamoto H, Saka S (2007) Influence of inorganic matter on wood pyrolysis at gasification temperature. J. Wood Sci.,53, 351-357.

2. Jensen A, Dam-Johansen K (1998) TG-FTIR study of the influence of potassium chloride on wheat straw pyrolysis. Energy Fuels 12: 929-938.

3. Shafizadeh F, Furneaux RH, Cochran T G, Scholl J P, Sakai Y (1979) Production of levoglucosan and glucose from pyrolysis of cellulose materials. J. Appl. Polymer. Sci. 23: 3525-3539.

4. Müller-Hagedorn M, Bockhorn H, Krebs L, Müller U (2003) A comparative kinetics study on the pyrolysis of three different wood species. J. Anal. Appl. Pyrolysis 68-69: 231-249.

5. Piskorz J, Radlein DStAG, Scott DS (1989) Pretreatment of wood and cellulose for production of sugars by fast pyrolysis. J. Anal. Appl. Pyrolysis 16: 127-142.

6. DeGroot WF, Shafizadeh F (1984) The influence of exchangeable cations on the carbonization of biomass. J. Anal. Appl. Pyrolysis 6: 217-232.

7. Pan W, Richards GN (1989) Influence of metal ions on volatile products of pyrolysis of wood. J. Anal. Appl. Pyrolysis: 16: 117-126.

8. Richards GN, Zheng G (1991) Influence of metal ions and of salts on products from pyrolysis of wood: applications to thermochemical processing of newsprint and biomass. J. Anal. Appl. Pyrolysis 21: 133-146.

9. Tsuchiya Y, Sumi K (1970) Thermal decomposition products of cellulose. J. Appl. Polymer Sci. 14: 2003-2013.

10. Fung DPC, Tsuchiya Y, Sumi K (1972) Thermal degradation of cellulose and levoglucosan - the effect of inorganic salts. Wood Sci. 5: 38-43.

11. Varhegyi G., Antal, Jr. MJ, Szekely T, Jakab E (1988) Simultaneous 
thermogravimetric-mass spectrometric studies of the thermal decomposition of biopolymers. 1. Avicel cellulose in the presence and absence of catalysts. Energy Fuels 2: 267-272.

12. Shafizadeh F, Sekiguchi Y (1983) Development of aromaticity in cellulosic chars. Carbon 21(5): 511-516.

13. Halpern Y, Patai S (1969) Pyrolytic reactions of carbohydrates. part VI. isothermal decomposition of cellulose in vacuo, in the presence of additives. Isr. J. Chem. 7: 685-690.

14. Madorsky SL, Hart VE, Straus S (1956) Pyrolysis of cellulose in a vacuum. J. Res. Natn. Bur. Stand. 56(6): 343-354.

15. Tsuchiya Y, Sumi K (1970) Thermal decomposition products of cellulose. J. Appl. Polymer Sci. 14: 2003-2013.

16. Halpern $\quad \mathrm{Y}$, Riffer R, Broido A (1973) Levoglucosenone (1,6-anhydro-3,4-dideoxy- $\Delta 3-\beta$-D-pyranosen-2-one). Major product of the acid-catalyzed pyrolysis of cellulose and related carbohydrates. J. Org. Chem. 38: 204-209.

17. Dobele G, Rossinskaja G, Telysheva G, Meier D, Faix O (1999) Cellulose dehydration and depolymerization reactions during pyrolysis in the presence of phosphoric acid. J. Anal. Appl. Pyrolysis 49: 307-317.

18. DeGroot WF, Shafizadeh F (1984) The influence of exchangeable cations on the carbonization of biomass. J. Anal. Appl. Pyrolysis 6: 217-232.

19. Kawamoto H, Murayam M, Saka S (2003) Pyrolysis behavior of levoglucosan as an intermediate in cellulose pyrolysis: polymerization into polysaccharide as a key reaction to carbonized product formation. J. Wood Sci. 49 (2003) 469-473.

20. Kawamoto H, Hatanaka W, Saka S (2003) Thermochemical conversion of cellulose 
in polar solvent (sulfolane) into levoglucosan and other low molecular-weight substances. J. Anal. Appl. Pyrolysis 70: 303-313.

21. Shimada N, Kawamoto H, Saka S (2007) Solid-state hydrolysis of cellulose and methyl $\alpha$ - and $\beta$-D-glucopyranosides in presence of magnesium chloride. Carbohydr. Res. 342: 1373-1377. 


\section{List of Figures}

Figure 1. Primary and secondary char formation.

Figure 2. Influence of the inorganic chlorides on primary and secondary char formation from cellulose $\left(\mathrm{N}_{2} / 400^{\circ} \mathrm{C} / 10 \mathrm{~min}\right)$.

Figure 3. Gel permeation chromatograms of the $\mathrm{MeOH}$-soluble fractions obtained from the chloride-impregnated cellulose samples $\left(\mathrm{N}_{2} / 400^{\circ} \mathrm{C} / 10 \mathrm{~min}\right)$.

Figure 4. Relationships between the primary, secondary and total char yields with the levoglucosan yield.

Figure 5. Gel permeation chromatograms of the heat treated mixtures of levoglucosan and chlorides (levoglucosan : chloride $=1: 0.1, \mathrm{~mol} / \mathrm{mol}, \mathrm{N}_{2} / 250^{\circ} \mathrm{C} / 1 \mathrm{~min}$ ). b: enlarged chromatograms.

Figure 6. Catalytic activities of the inorganic chlorides on the polymerization of levoglucosan (levoglucosan : chloride $=1: 0.1, \mathrm{~mol} / \mathrm{mol}, \mathrm{N}_{2} / 250^{\circ} \mathrm{C} / 1 \mathrm{~min}$ ). *1: peak area (higher MW products than levoglucosan) / peak area (levoglucosan) in GPC.

Figure 7. Levoglucosan as a key intermediate for the secondary char formation in cellulose pyrolysis. 


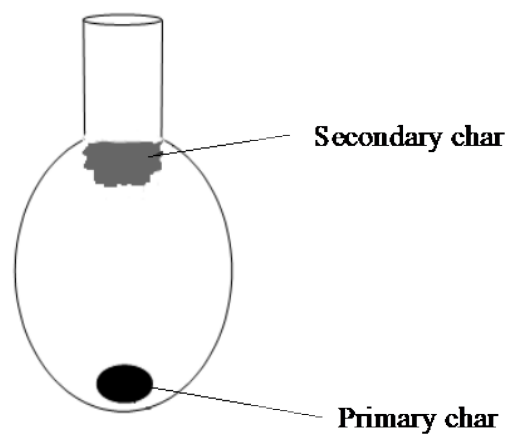

Figure 1. Primary and secondary char formation. 


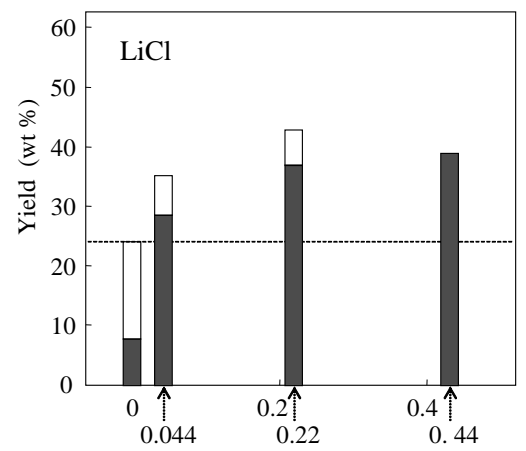

Content of inorganic chloride (mol / mol of glucose-repeating unit)

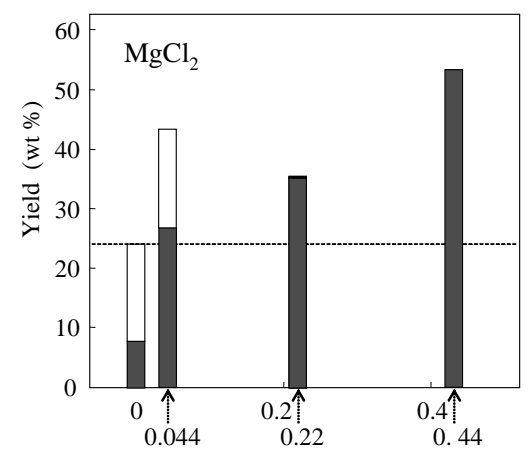

Content of inorganic chloride (mol / mol of glucose-repeating unit)

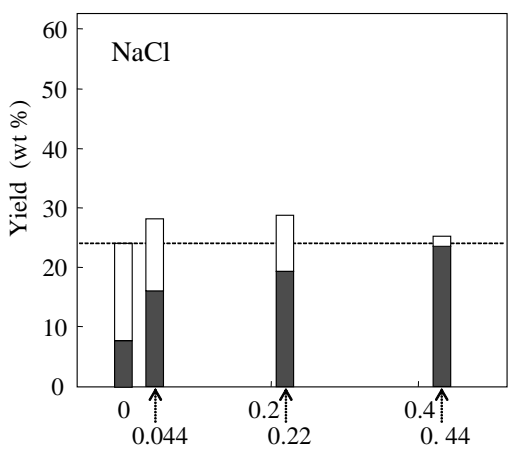

Content of inorganic chloride (mol / mol of glucose-repeating unit)

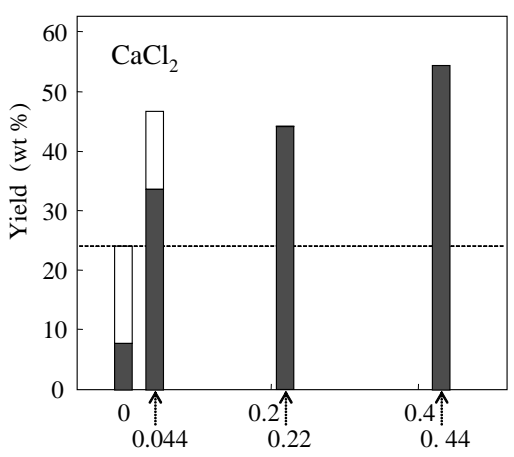

Content of inorganic chloride (mol / mol of glucose-repeating unit)

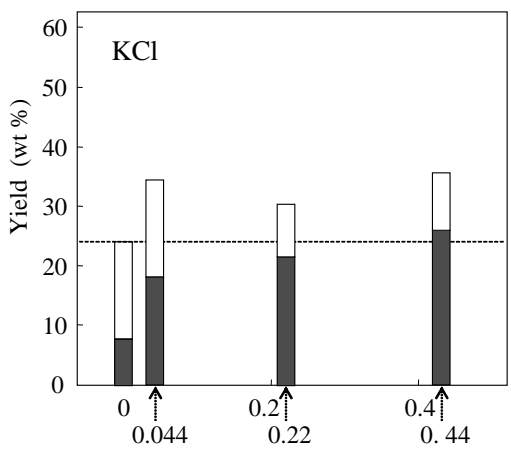

Content of inorganic chloride (mol / mol of glucose-repeating unit)

Figure 2. Influence of the inorganic chlorides on primary and secondary char formation from cellulose $\left(\mathrm{N}_{2} / 400^{\circ} \mathrm{C} / 10 \mathrm{~min}\right)$. 


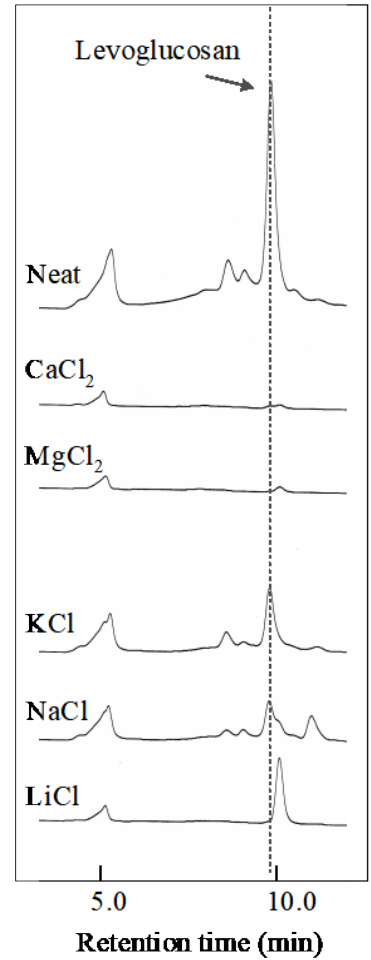

Figure 3. Gel permeation chromatograms of the $\mathrm{MeOH}$-soluble fractions obtained from the chloride-impregnated cellulose samples $\left(\mathrm{N}_{2} / 400^{\circ} \mathrm{C} / 10 \mathrm{~min}\right)$. 


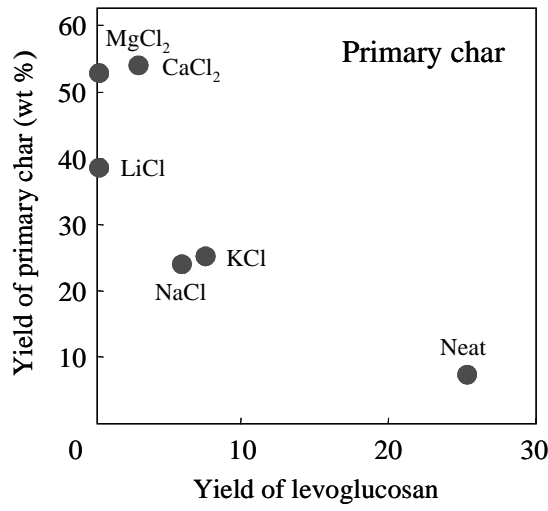

(mol \%, based on glucose-repeating unit)

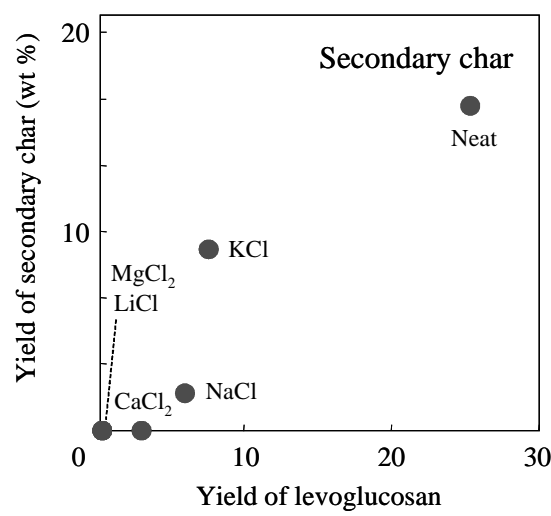

(mol \%, based on glucose-repeating unit)

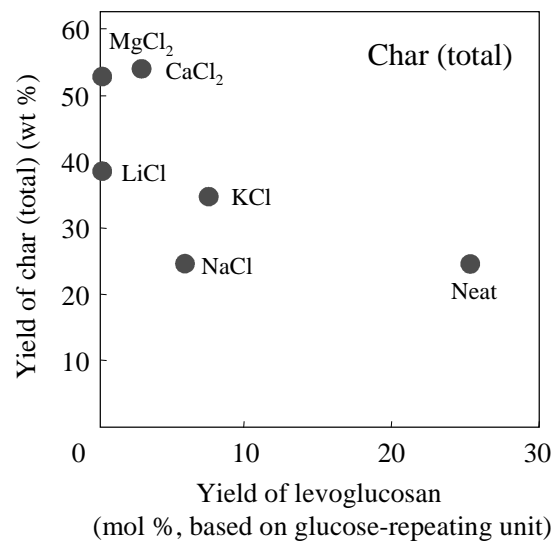

Figure 4. Relationships between the primary, secondary and total char yields with the levoglucosan yield. 


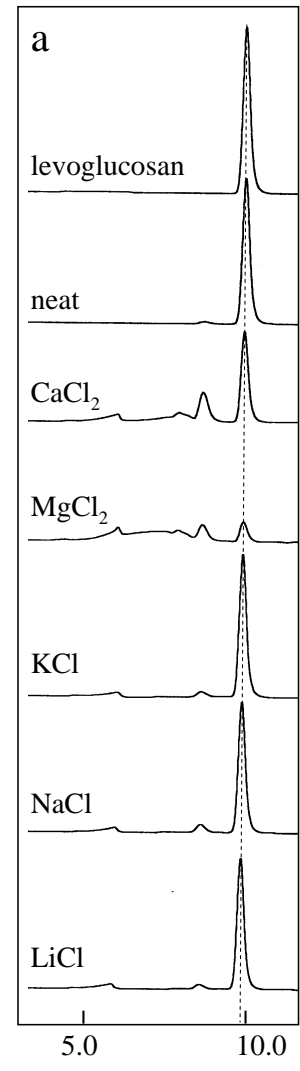

Retention time (min)

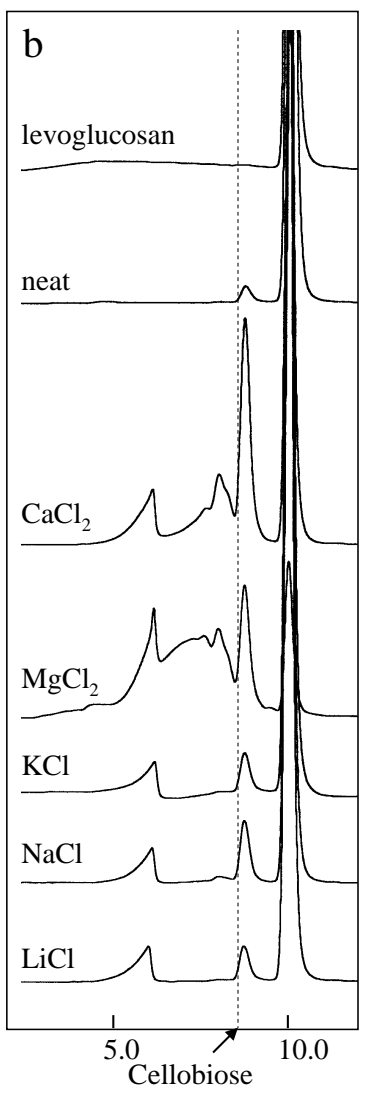

Retention time (min)

Figure 5. Gel permeation chromatograms of the heat treated mixtures of levoglucosan and chlorides (levoglucosan : chloride $=1: 0.1, \mathrm{~mol} / \mathrm{mol}, \mathrm{N}_{2} / 250^{\circ} \mathrm{C} / 1$ $\min )$.

b: enlarged chromatograms. 


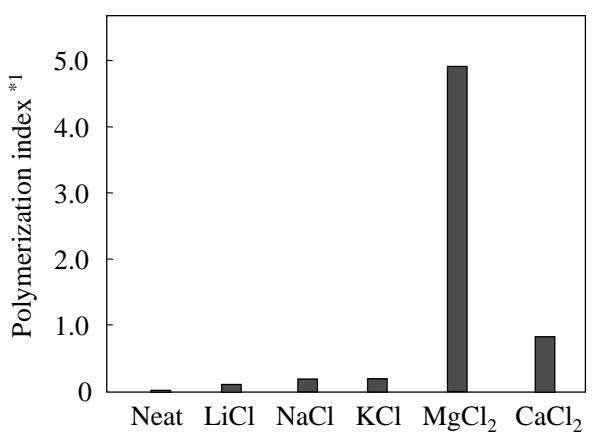

Figure 6. Catalytic activities of the inorganic chlorides on the polymerization of levoglucosan (levoglucosan : chloride $=1: 0.1, \mathrm{~mol} / \mathrm{mol}, \mathrm{N}_{2} / 250^{\circ} \mathrm{C} / 1$ $\min )$.

*1: peak area (higher MW products than levoglucosan) / peak area (levoglucosan) in GPC. 


\section{Levoglucosan $\rightarrow$ Secondary char}
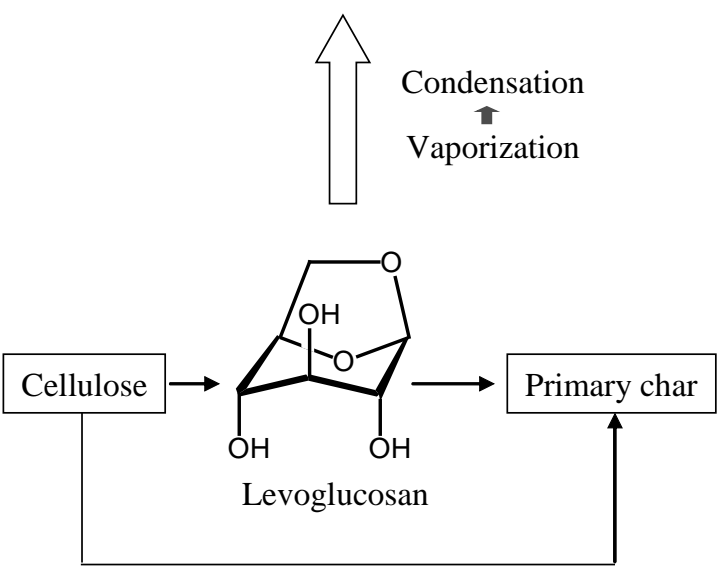

Figure 7. Levoglucosan as a key intermediate for the secondary char formation in cellulose pyrolysis. 